\title{
Healthy whole-grain choices for children and parents: a multi-component school-based pilot intervention
}

\author{
Teri L Burgess-Champouxt, Hing Wan Chan, Renee Rosen, Len Marquart and \\ Marla Reicks* \\ Department of Food Science and Nutrition, University of Minnesota, 1334 Eckles Avenue, $225 \mathrm{FScN}$, \\ St. Paul, MN 55108, USA
}

Submitted 9 October 2006: Accepted 11 October 2007: First published online 7 December 2007

\begin{abstract}
Objective: The aim of the present study was to pilot-test a school-based intervention designed to increase consumption of whole grains by 4th and 5 th grade children.

Design: This multi-component school-based pilot intervention utilised a quasiexperimental study design (intervention and comparison schools) that consisted of a five-lesson classroom curriculum based on Social Cognitive Theory, school cafeteria menu modifications to increase the availability of whole-grain foods and family-oriented activities. Meal observations of children estimated intake of whole grains at lunch. Children and parents completed questionnaires to assess changes in knowledge, availability, self-efficacy, usual food choice and role modelling. Setting/sample: Parent/child pairs from two schools in the Minneapolis metropolitan area; 67 in the intervention and 83 in the comparison school.

Results: Whole-grain consumption at the lunch meal increased by 1 serving $(P<0 \cdot 0001)$ and refined-grain consumption decreased by 1 serving for children in the intervention school compared with the comparison school post-intervention $(P<0 \cdot 001)$. Whole-grain foods were more available in the lunches served to children in the intervention school compared with the comparison school postintervention $(P<0 \cdot 0001)$. The ability to identify whole-grain foods by children in both schools increased, with a trend towards a greater increase in the intervention school $(P=0 \cdot 06)$. Parenting scores for scales for role modelling $(P<0 \cdot 001)$ and enabling behaviours $(P<0 \cdot 05)$ were significantly greater for parents in the intervention school compared with the comparison school post-intervention.

Conclusions: The multi-component school-based programme implemented in the current study successfully increased the intake of whole-grain foods by children.
\end{abstract}

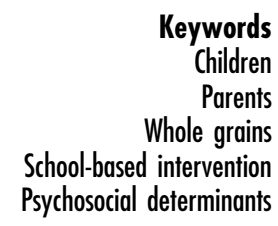

Substantial scientific evidence suggests an inverse association between the intake of whole grains and the risk of coronary heart disease, type 2 diabetes, obesity and certain cancers ${ }^{(1,2)}$. Consumption of three servings of whole grains per day has been collectively recommended by numerous government and non-governmental agencies $^{(3-6)}$. Despite these recommendations, recent data from the National Health and Nutrition Examination Survey (1999-2002) showed that children and adolescents 6-19 years of age consumed only $0.8-1.0$ mean servings of whole-grain products per day ${ }^{(7)}$.

Overseen by the US Department of Agriculture, the National School Lunch Program provides school lunch to approximately 30 million children on a daily basis ${ }^{(8)}$. Schools are an appropriate setting for delivering

$\dagger$ Currently at Department of Food and Nutrition, College of Human Development, University of Wisconsin-Stout, Menomonie, WI, USA. programmes to change eating behaviours because young people between the ages of 5 and 17 years can be exposed to new foods on repeated occasions through school meals.

Social Cognitive Theory (SCT) provides a theoretical foundation for identifying modifiable behaviours and for structuring behaviour-change interventions. This theory explains human behaviour in terms of a triadic, dynamic and reciprocal relationship in which personal factors, behaviour and environmental influences interact ${ }^{(9)}$. SCT has provided the theoretical framework for several multi-component school-based interventions involving children and parents that resulted in positive dietary behaviour change ${ }^{(9,10)}$. Theory constructs addressed in previous interventions included individual factors such as self-regulation (goal-setting and problem-solving skills), self-efficacy (confidence to carry out behaviours successfully) and outcome expectancies (preferences), 
behavioural factors such as behavioural capability (food and nutrition knowledge and behavioural skills) and usual food choice (choice between pairs of foods), and environmental factors including the availability/accessibility of foods ${ }^{(10)}$.

The purpose of the present study was to describe the development, pilot-testing and efficacy of a multi-component, pilot school-based intervention aimed to increase the consumption of whole grains by 4 th and 5 th grade children. To our knowledge, this is the first pilot schoolbased intervention that has focused on whole grains and children. It was hypothesised that, compared with children in the comparison school post-intervention, children in the intervention school would: (1) increase their consumption of whole grains by 0.5 serving per day; and (2) have increased availability of whole-grain foods in the school cafeteria and home.

\section{Methods}

\section{Subjects}

Two suburban elementary schools from the Minneapolis metropolitan area were recruited to participate in this pilot efficacy trial, which was implemented from January to May 2005. Schools with similar demographic characteristics, size and number of 4th and 5 th grade students were assigned to the intervention and comparison conditions on a non-randomised basis. School district personnel provided recommendations for selection of the two schools based on a similar cooperative nature on the part of school food service and administrative staff in both schools. Parent/child pairs were recruited via a two-wave mailing letter sent home from school along with a letter from the principal encouraging participation. All 4th and 5th grade students were eligible to participate except for 5 th grade band students due to scheduling conflicts (Fig. 1).

The study was approved by the University of Minnesota Institutional Review Board Human Subjects Protection Committee and the Hopkins School District Research Committee. Parent and child participants signed consent and assent forms, respectively, and were given $\$ 10-50$ for their participation.

\section{Intervention components and measures}

Overview

The 'Power of 3: Get Healthy with Whole Grain Foods' pilot intervention programme contained three main components addressing environmental, personal and behavioural factors derived from SCT: a five-lesson classroom curriculum, school cafeteria menu changes, and family involvement. A quasi-experimental study design was utilised to determine the efficacy of the pilot programme to increase the consumption of whole grains by children and modify the availability of whole-grain foods in the home and school environments. Process evaluation measures assessed the fidelity of the programme implementation and the level of participation by children and parents.

\section{Classroom curriculum component}

The 'Power of 3: Get Healthy with Whole Grain Foods', a five-lesson classroom curriculum based on SCT, was developed and taught to children enrolled in the study on a weekly basis in the intervention school cafeteria by trained research assistants. A teacher and/or the principal attended each of the classroom lessons to provide disciplinary assistance as needed. These lessons were supplementary to the standard school curriculum.

Learning objectives and developmentally appropriate activities were based on formative data from focus group discussions ${ }^{(11)}$. Lessons were initially pilot-tested with 5 th grade children in another school within this school district. The overall aim of this educational programme was to improve instrumental knowledge to identify whole-grain foods, enhance self-efficacy through practical experiences that emphasised selecting, tasting and preparing whole-grain foods, build menu-planning skills, practice goal-setting, and to encourage advocacy for peers and family members to increase their intake of whole-grain foods (Table 1). Each 45-minute lesson included sampling of whole-grain products and incorporation of a variety of hands-on learning experiences such as grain identification, hand milling grains into flour, reading labels, preparation of snacks, menu planning, and participation in a debate. Each child received a curriculum workbook and a set of flash cards (i.e. 'Quiz Bowl Cards') that contained questions regarding the key concepts discussed in class.

\section{School cafeteria menu changes}

The school cafeteria component focused on menu planning, product procurement, training, and quality control measures. Working with the school district nutritionist and food service director, intervention staff recommended school cafeteria menu modifications to increase the availability of whole-grain foods served to children in the intervention school. The overall goal was to offer the equivalent of one whole-grain serving to children on a daily basis at lunch by replacing refined-grain products with whole or partial whole-grain counterparts. Targeted food products included pizza, pasta, tortillas, buns and rolls made with white and red whole wheat flour or barley flour. Wholegrain products were provided by a food manufacturer or a local vendor for school lunch meals and take-home snacks. Grant funding offset additional costs associated with the proposed menu changes. New products were sampled and evaluated by intervention and food service staff prior to incorporation into the school meals.

School food service staff (cook manager and all serving staff) attended a one-hour training session regarding the programme objectives. Site visits were made by the 


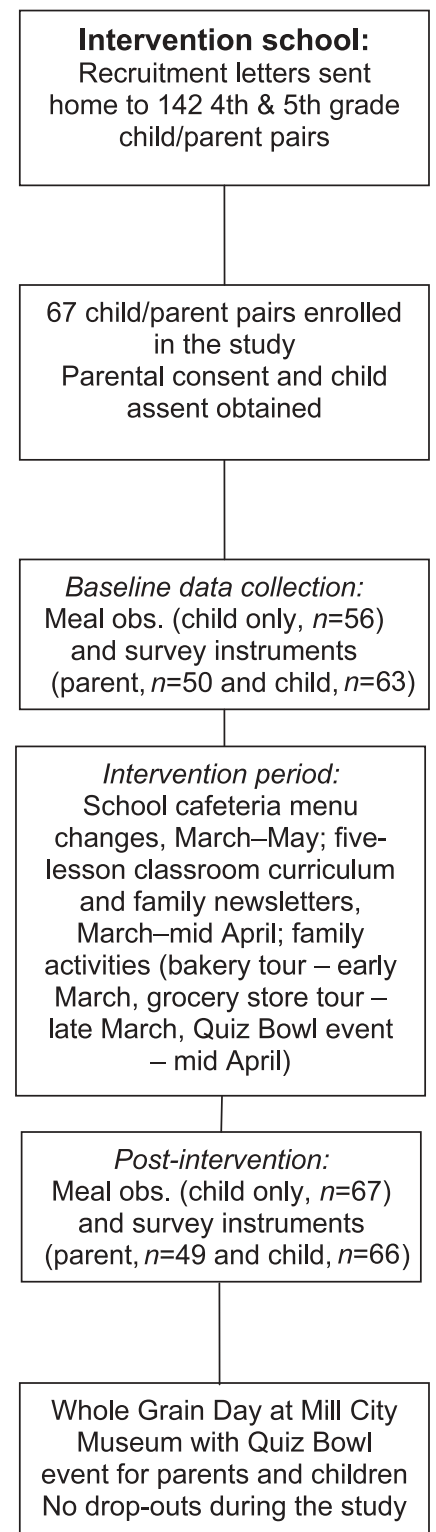

Fig. 1 Flow diagram of the study design

research staff two or three times per week throughout the intervention to monitor implementation of the proposed menu changes. A quality control log was completed during each visit and feedback was provided to the food service supervisor. Randomly selected one-week menus were analysed for whole-grain content before and after the intervention. School meals at both the intervention and comparison schools provided 0.09 (standard deviation $0 \cdot 17$ ) mean servings of whole grains per day at baseline. No differences in the availability of whole-grain foods included in school meals were noted at baseline between the intervention and comparison schools.

\section{Family component}

The family component included weekly parent newsletters, bakery and grocery store tours, and a "Whole

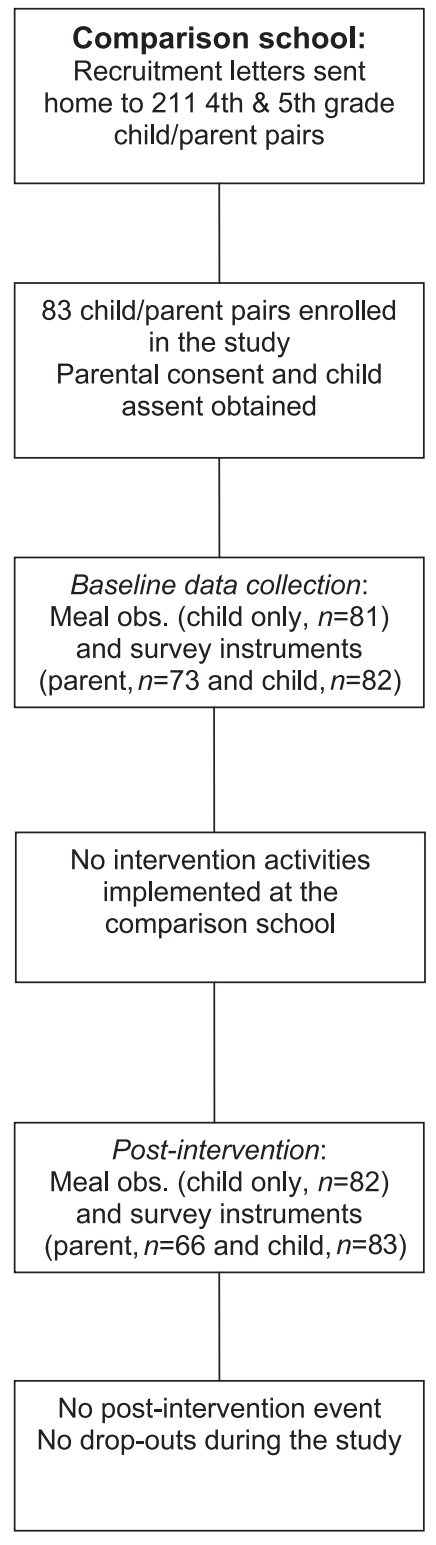

Grain Day' event at a local milling museum. The overall aim of the family component was to increase the availability of whole-grain foods in the home environment, to encourage parental role modelling for consuming wholegrain foods, and to promote a dialogue between parents and children regarding the inclusion of whole-grain foods within the context of a healthy diet.

Local bakery tours led by a character depicting a kernel of wheat provided children and their families with an up-close view of grain milling and bread preparation ${ }^{(12)}$. The grocery tour programme included a brief classroom lesson combined with a guided tour. Parent/child pairs received a 'Hunt for Whole Grains' treasure map which they utilised to learn strategies for identifying whole-grain foods ${ }^{(13)}$. At the conclusion of the intervention programme, children and their families were invited to attend a 'Whole 
Table 1 Social Cognitive Theory (SCT) concepts and application

\begin{tabular}{|c|c|c|c|}
\hline SCT constructs & $\begin{array}{l}\text { Application (school cafeteria, } \\
\text { classroom activities and family } \\
\text { newsletters/events) }\end{array}$ & Learning activities & Measures \\
\hline \multicolumn{4}{|c|}{ Behavioural Domain } \\
\hline $\begin{array}{l}\text { Behavioural } \\
\text { capability }\end{array}$ & $\begin{array}{l}\text { Provided instrumental knowledge } \\
\text { to identify and eat whole-grain } \\
\text { foods }\end{array}$ & $\begin{array}{l}\text { - Identification: matched grain samples in test tubes } \\
\text { with names } \\
\text { - Labelled parts of a diagram of a whole grain kernel } \\
\text { - Parent newsletter activity matching common } \\
\text { grains and their food products } \\
\text { - Participation in Whole Grain Quiz Bowl event }\end{array}$ & $\begin{array}{l}\text { Whole-grain knowledge } \\
\text { scale (identified which } \\
\text { foods were whole-grain } \\
\text { from two options) }\end{array}$ \\
\hline $\begin{array}{l}\text { Usual food } \\
\text { choice }\end{array}$ & $\begin{array}{l}\text { Served a variety of whole-grain } \\
\text { foods in the school cafeteria for } \\
\text { lunch }\end{array}$ & $\begin{array}{l}\text { - Used the Food Guide Pyramid to locate grain } \\
\text { group and grain foods } \\
\text { - Tasted and rated whole- and refined-grain food } \\
\text { samples for taste, texture, appearance and accep- } \\
\text { tance } \\
\text { - Used food labels to identify foods as whole- or } \\
\text { refined-grain } \\
\text { - Used common household items to understand } \\
\text { portion sizes } \\
\text { - Parent newsletter activity that used the school } \\
\text { menu to identify whole-grain foods } \\
\text { - Identified whole-grain products during grocery } \\
\text { store tour using treasure map }\end{array}$ & $\begin{array}{l}\text { Usual food choice scale } \\
\text { (which would you pick? } \\
\text { child presented with } \\
\text { whole- or refined-grain } \\
\text { foods) }\end{array}$ \\
\hline \multicolumn{4}{|c|}{ Individual or Personal Domain } \\
\hline Self-efficacy & $\begin{array}{l}\text { Provided practical experiences } \\
\text { that emphasised selecting, } \\
\text { tasting and preparing whole- } \\
\text { grain foods as well as menu } \\
\text { planning and shopping skills }\end{array}$ & $\begin{array}{l}\text { - Problem-solving activity to overcome barriers to } \\
\text { selecting and eating whole-grain foods } \\
\text { - Menu planning and shopping list exercises } \\
\text { - Parent newsletter with whole-grain recipes to } \\
\text { prepare and serve at home }\end{array}$ & $\begin{array}{l}\text { Self-efficacy to choose } \\
\text { whole-grain foods } \\
\text { scale (rated confidence } \\
\text { to eat whole-grain } \\
\text { foods in a variety of }\end{array}$ \\
\hline $\begin{array}{l}\text { Self-regulation/ } \\
\text { self-control }\end{array}$ & $\begin{array}{l}\text { Provided opportunities to practice } \\
\text { goal-setting and monitoring }\end{array}$ & $\begin{array}{l}\text { - Food preparation activities } \\
\text { - Review recommended number of daily whole- } \\
\text { grain servings } \\
\text { - Estimate actual intake of whole-grain foods } \\
\text { - Set goals to meet recommendations for daily } \\
\text { whole-grain servings }\end{array}$ & situations) \\
\hline Reinforcements & $\begin{array}{l}\text { Provided opportunity to record } \\
\text { progress and reward successful } \\
\text { goal attainment }\end{array}$ & $\begin{array}{l}\text { - Monitored progress of goal achievement using } \\
\text { tracking forms. Verbal feedback }\end{array}$ & \\
\hline $\begin{array}{l}\text { Outcome } \\
\text { expectations }\end{array}$ & $\begin{array}{l}\text { Provided information about health } \\
\text { benefits of eating whole-grain } \\
\text { foods }\end{array}$ & $\begin{array}{l}\text { - Debate between two whole-grain characters } \\
\text { regarding health benefits } \\
\text { - Parent newsletter with tips for family conversations } \\
\text { about reasons for selecting whole-grain foods }\end{array}$ & \\
\hline \multicolumn{4}{|c|}{ Environmental Domain } \\
\hline Availability & $\begin{array}{l}\text { Provided activities to encourage } \\
\text { advocacy for family members } \\
\text { and school food service to } \\
\text { increase availability of whole- } \\
\text { grain foods in meals and snacks }\end{array}$ & $\begin{array}{l}\text { - Parent newsletter activity to complete a home } \\
\text { inventory of whole-grain foods with child } \\
\text { - Letter-writing activity to advocate for more whole- } \\
\text { grain foods in school and at home }\end{array}$ & $\begin{array}{l}\text { Availability of whole-grain } \\
\text { foods in the home } \\
\text { scale }\end{array}$ \\
\hline $\begin{array}{l}\text { Observational } \\
\text { learning }\end{array}$ & $\begin{array}{l}\text { Served a variety of whole-grain } \\
\text { foods in the school cafeteria for } \\
\text { lunch. Ate lunch meal with } \\
\text { school peers }\end{array}$ & $\begin{array}{l}\text { - Bakery and grocery store tours with whole-grain } \\
\text { product samples } \\
\text { - Whole-grain cooking demonstration for families } \\
\text { - Observed steps involved in making whole-grain } \\
\text { bread products during bakery tour }\end{array}$ & \\
\hline
\end{tabular}

Grain Day' at a local milling museum. Children participated in a Quiz Bowl event to demonstrate their acquired knowledge and skills regarding whole-grain foods.

\section{Measurement}

\section{Measures with children}

Dietary intake of children. Pre/post lunch meal observations of children were conducted at both the intervention and comparison school to estimate wholegrain intake at lunch. Each child was observed once at baseline and again post-intervention. Intervention staff completed ten hours of combined didactic and practicum training that focused on visual portion size estimation and data entry. To determine the amount of food consumed by each child, meal observers recorded the amount of each food served at the beginning of lunch and subtracted the measured amounts remaining on the tray at the end of lunch.

Challenges inherent to direct meal observation include ensuring adequate agreement among multiple observers, recording the intake of children who consume packed 
lunches prepared at home, and limits regarding the number of children who can be observed simultaneously $^{(14-16)}$. To ensure a high level of consistency between the different observers $(n=5)$, interobserver reliability assessments were completed at baseline and throughout the intervention. Previous studies have defined an adequate level of agreement as $\geq 85 \%(15,17)$. Overall mean agreement across the five observers based on six assessments was $91 \%$.

Meal observation and menu data were analysed using the Nutrition Data System for Research software, version 2005 (University of Minnesota, St. Paul, MN, USA), by a Nutrition Coordinating Center-certified interviewer. Servings of whole grains were calculated using the food group serving count system (based on the 2005 Dietary Guidelines for Americans ${ }^{(18)}$ ), which categorises grain and grain-based products into three subgroups: whole grain (WG), some whole grain (SWG) and refined grain (RG). WG was defined as a product in which the first ingredient on the label is a whole grain; SWG included products containing a whole-grain or partial whole grainingredient anywhere else on the label; and RG included products with no whole-grain ingredients on the label. No differences in whole-grain consumption by children for the three grain categories or for associated nutrient intake were noted between the intervention and comparison schools at baseline.

Measurement variables related to SCT for children. A questionnaire designed to assess psychosocial variables for children - specifically knowledge, usual food choice, availability and self-efficacy - was developed and tested prior to use in this intervention. Development of the questionnaire items was based on existing instruments tested and validated regarding intake of other foods ${ }^{(19-22)}$. Internal consistency for the child scales ranged from 0.48 to 0.74 . The group-administered questionnaire contained multiple choice, yes/no and 3- to 5-point scale items.

Ability to identify a whole-grain food when given two options (i.e. whole- vs. refined-grain products) reflected knowledge and was measured using a 7-item scale in which summed scores ranged from 0 to 6 with 1 point assigned to each correct answer (i.e. brown rice vs. white rice). Usual food choice was measured using a 7-item scale in which summed scores ranged from -7 to +7 with 1 point assigned to each whole-grain choice (i.e. 'Which rice would you choose to eat?: Brown rice or white rice'). Availability of whole-grain foods in the home was measured using a 9-item scale in which summed scores ranged from 9 to 27 (i.e. 'In my home there is whole-grain bread for me to have a sandwich: almost never $=1$, sometimes $=2$, or almost always $=3$ '). Self-efficacy was measured using a 7-item scale in which summed scores ranged from 7 to 21 (i.e. 'I can pick whole-grain foods even when my friends don't choose them: I'm not sure I can $=1$, I'm a little bit sure I can $=2$, or I know I can $=3$ ').

\section{Measures with parents}

Measurement variables related to SCT for parents. A questionnaire designed to assess psychosocial variables for parents - specifically frequency of whole-grain intake, availability of whole-grain foods in the home and role modelling - was also developed and tested prior to use in this pilot intervention. Development of the questionnaire items was based on existing instruments tested and validated regarding intake of other foods ${ }^{(19,23)}$. The self-administered questionnaire containing multiple choice, yes/no and 3- to 5-point scale items was completed at home by parents and returned to school. A 12-item food frequency section modified from the Block Food Frequency Questionnaire ${ }^{(24)}$ measured the frequency of consuming selected whole- and refined-grain foods over the past month. Frequency intervals ranged from never to two or more times per week. Availability of whole-grain foods in the home over the past week was measured using a 12-item scale (including nine whole-grain and three refined-grain foods) and response options of yes or no.

Additional items regarding parental modelling, enabling behaviours and expectations $(n=17)$ were subjected to principal components analysis ${ }^{(25)}$. An a priori determination using theoretical constructs from SCT yielded three distinct subscales for parents: a role modelling scale (five items) (i.e. 'How often do you set an example for your child by doing the following: eat whole-grain cereal for breakfast; scaled from 1 to 5 where never $=1$, rarely $=2$, some of the time $=3$, most of the time $=4$, or always $=5$ '), an enabling behaviour scale (four items) (i.e. 'How often do you buy whole-grain foods when shopping for groceries: scaled from 1 to 5 where never $=1$, rarely $=2$, some of the time $=3$, most of the time $=4$, or always $=5$ '), and a wholegrain health benefits scale (three items) (i.e. 'Getting enough whole grains can help me have a healthy weight: scaled from 1 to 5 where strongly disagree $=1$, disagree $=2$, don't know $=3$, agree $=4$, or strongly agree $=5^{\prime}$ ). Internal consistency for the three parent scales ranged from $0 \cdot 63$ to $0 \cdot 81$.

\section{Statistical analyses}

Data were analysed using the Statistical Analysis System statistical software package version 9.1.3 (SAS Institute, Cary, NC, USA). All $P$ values were two-sided and the significance level was set at $P<0 \cdot 05$. Descriptive statistics were used to describe demographic characteristics, intake of whole-grain foods, process evaluation measures and psychosocial variables related to SCT. Whole-grain intake of children, a continuous independent variable, was adjusted for positive skewness with log transformation. Paired $t$ tests were used to determine differences between the pre- and post-test measures for children and parents in both the intervention and comparison schools. Analysis of variance was used to detect significant changes in difference values between the intervention and comparison schools. Cronbach alpha coefficients were calculated to assess the internal consistency for each scale. With only 
one school per condition it is impossible to deconfound the experimental effect from any school-by-time component of variance arising from homogeneity of change with schools ${ }^{(26)}$. In the discussion of study limitations below we use an external estimate of the intraclass correlation (ICC) for change to indicate that the major conclusions are robust to this limitation. For this feasibility study, for simplicity, we present standard errors without inflation.

\section{Results}

\section{Demographic characteristics of participants}

A total of 67 parent/child pairs in the intervention school and 83 parent/child pairs in the comparison school participated in this pilot study. Mean age of the children was 10 years with approximately 45\% male and 55\% female. About half were in the 4 th grade and half in the 5 th grade. Frequency of consuming school lunch three or more times per week was similar for children in both schools at baseline. Nearly all children lived in households with two adults. Mean age of the parents was 40 years, the majority were female, welleducated, and approximately half were employed full-time. There were no significant differences in demographic characteristics for participants in the intervention and comparison schools at baseline except for race. Our intervention sample was $48 \%$ white versus $72 \%$ white for the total group of eligible 4th and 5th grade students. Demographic characteristics of the participants are presented in Tables 2 and 3.

\section{Intervention effects for children}

Intake of whole-grain foods and food service outcomes There was significantly greater availability of whole-grain foods in the lunches of children in the intervention school compared with the comparison school post-intervention $(P<0 \cdot 0001)$ (Table 4). Availability was assessed by the intervention staff using selected meal observation days and included both food items purchased from school meals and packed lunches prepared at home. In the intervention school, an average of 0.09 mean WG servings were offered to children per day pre-intervention (i.e. foods with a whole grain as the first ingredient; based on eight menu days over a three-week period). However, during the post-intervention period, an average of 1.7 mean WG servings were offered to children per day (based on seven menu days over a three-week period).

A positive change suggested by the intake data from this pilot study was that consumption of whole grains at the lunch meal increased by approximately 1 serving

Table 2 Demographic characteristics of the children at baseline

\begin{tabular}{|c|c|c|c|c|c|c|c|}
\hline \multirow[b]{2}{*}{ Child characteristic } & \multicolumn{3}{|c|}{ Intervention school } & \multicolumn{3}{|c|}{ Comparison school } & \multirow[b]{2}{*}{$P$ value } \\
\hline & Mean & SD & $n$ & Mean & $\mathrm{SD}$ & $n$ & \\
\hline \multirow[t]{2}{*}{ Age (years) $\dagger$} & $10 \cdot 2$ & $0 \cdot 8$ & 63 & $10 \cdot 2$ & $0 \cdot 7$ & 82 & $0 \cdot 87$ \\
\hline & $\%$ & $n$ & & $\%$ & $n$ & & \\
\hline \multicolumn{8}{|l|}{ Gradeł } \\
\hline 4th & $46 \cdot 0$ & 29 & & $48 \cdot 8$ & 40 & & 0.74 \\
\hline 5th & $54 \cdot 9$ & 34 & & $51 \cdot 2$ & 42 & & \\
\hline \multicolumn{8}{|l|}{ Gender,$\S$} \\
\hline Girls & $52 \cdot 3$ & 33 & & $57 \cdot 3$ & 47 & & 0.55 \\
\hline Boys & $47 \cdot 6$ & 30 & & $42 \cdot 7$ & 35 & & \\
\hline \multicolumn{8}{|c|}{ Lives in home with parentł } \\
\hline Mother & $93 \cdot 7$ & 59 & & $98 \cdot 8$ & 81 & & 0.09 \\
\hline Father & $73 \cdot 0$ & 46 & & $87 \cdot 8$ & 72 & & 0.02 \\
\hline \multicolumn{8}{|l|}{ Race/ethnicity $\ddagger$,\| } \\
\hline Hispanic & $6 \cdot 4$ & 4 & & $6 \cdot 1$ & 5 & & 0.95 \\
\hline Asian & $3 \cdot 2$ & 2 & & $6 \cdot 1$ & 5 & & 0.42 \\
\hline Black & $17 \cdot 5$ & 11 & & $4 \cdot 9$ & 4 & & 0.01 \\
\hline White & $47 \cdot 6$ & 30 & & $75 \cdot 6$ & 62 & & 0.0005 \\
\hline American Indian & $9 \cdot 5$ & 6 & & $6 \cdot 1$ & 5 & & 0.47 \\
\hline Other & $23 \cdot 8$ & 15 & & $7 \cdot 3$ & 6 & & 0.005 \\
\hline Eats school lunch $\ddagger, \S$ & & 61 & & & 81 & & $0 \cdot 72$ \\
\hline Never & $19 \cdot 7$ & 12 & & $14 \cdot 8$ & 12 & & \\
\hline 1 to 2 times/week & $18 \cdot 0$ & 11 & & $17 \cdot 3$ & 14 & & \\
\hline$\geq 3$ times/week & $62 \cdot 3$ & 38 & & $67 \cdot 9$ & 55 & & \\
\hline Eats packed lunch $\ddagger, \S$ & & 62 & & & 81 & & $0 \cdot 26$ \\
\hline Never & $41 \cdot 9$ & 26 & & $34 \cdot 6$ & 28 & & \\
\hline 1 to 2 times/week & $17 \cdot 7$ & 11 & & $29 \cdot 6$ & 24 & & \\
\hline$\geq 3$ times/week & $40 \cdot 3$ & 25 & & $35 \cdot 8$ & 29 & & \\
\hline
\end{tabular}

SD, standard deviation.

$+P$ value based on $t$ test statistic

$\ddagger P$ value based on $\chi^{2}$ statistic.

§Percentages may not add up to 100 due to rounding.

॥Percentages $>100$ reflect that children could mark more than one race/ethnicity category. 
Table 3 Demographic characteristics of the parents at baseline

\begin{tabular}{|c|c|c|c|c|c|c|c|}
\hline \multirow[b]{2}{*}{ Parent characteristic } & \multicolumn{3}{|c|}{ Intervention school } & \multicolumn{3}{|c|}{ Comparison school } & \multirow[b]{2}{*}{$P$ value } \\
\hline & Mean & SD & $n$ & Mean & SD & $n$ & \\
\hline Age (years) $\dagger$ & $39 \cdot 7$ & $6 \cdot 4$ & 47 & $41 \cdot 8$ & $5 \cdot 3$ & 72 & $0 \cdot 17$ \\
\hline \multirow[t]{2}{*}{ Number of adults in the homet } & $1 \cdot 9$ & $0 \cdot 7$ & 49 & 1.9 & 0.5 & 72 & $0 \cdot 73$ \\
\hline & $\%$ & $n$ & & $\%$ & $n$ & & \\
\hline \multicolumn{7}{|l|}{ Genderł,§ } & 0.30 \\
\hline Women & $85 \cdot 7$ & 42 & & $91 \cdot 7$ & 66 & & \\
\hline Men & $14 \cdot 3$ & 7 & & $8 \cdot 3$ & 6 & & \\
\hline \multicolumn{7}{|l|}{ Education $\ddagger, \S$} & 0.06 \\
\hline Up to 8th grade & 0.0 & 0 & & $1 \cdot 4$ & 1 & & \\
\hline Some high school & $4 \cdot 2$ & 2 & & 0.0 & 0 & & \\
\hline High-school graduate or GED & $10 \cdot 4$ & 5 & & $1 \cdot 4$ & 1 & & \\
\hline Some college or technical school & $27 \cdot 1$ & 13 & & $26 \cdot 8$ & 19 & & \\
\hline $\begin{array}{l}\text { College graduate (4-year college or } \\
\text { university or advanced degree) }\end{array}$ & $58 \cdot 3$ & 28 & & $70 \cdot 4$ & 50 & & \\
\hline \multicolumn{8}{|l|}{ Employment status $¥ \S$} \\
\hline Student & $8 \cdot 3$ & 4 & & $1 \cdot 4$ & 1 & & 0.06 \\
\hline Homemaker & $20 \cdot 8$ & 10 & & $18 \cdot 1$ & 13 & & $0 \cdot 70$ \\
\hline Not employed & $4 \cdot 2$ & 2 & & 0.0 & 0 & & 0.08 \\
\hline Employed part-time & $27 \cdot 1$ & 13 & & $22 \cdot 2$ & 16 & & 0.54 \\
\hline Employed full-time & $45 \cdot 8$ & 22 & & $58 \cdot 3$ & 42 & & $0 \cdot 18$ \\
\hline Retired & $2 \cdot 1$ & 1 & & $0 \cdot 0$ & 0 & & 0.22 \\
\hline \multicolumn{8}{|l|}{ Race/ethnicity $\ddagger$ } \\
\hline Hispanic & $4 \cdot 4$ & 2 & & $4 \cdot 4$ & 3 & & 1.00 \\
\hline Asian & $6 \cdot 3$ & 3 & & $5 \cdot 6$ & 4 & & $0 \cdot 89$ \\
\hline Black & $12 \cdot 5$ & 6 & & $1 \cdot 4$ & 1 & & 0.01 \\
\hline White & $72 \cdot 9$ & 35 & & $91 \cdot 6$ & 65 & & 0.006 \\
\hline Other & $8 \cdot 3$ & 4 & & $2 \cdot 8$ & 2 & & $0 \cdot 18$ \\
\hline
\end{tabular}

SD, standard deviation; GED, General Educational Development.

$+P$ value based on $t$ test statistic.

$\ddagger P$ value based on $\chi^{2}$ statistic.

$\S$ Percentages may not add up to 100 due to rounding.

$(P<0 \cdot 0001)$ and consumption of refined grains decreased by approximately 1 serving $(P<0 \cdot 001)$ for children in the intervention school compared with the comparison school post-intervention. Table 4 summarises the changes in grain, energy and nutrient intakes by category for children. Changes in intakes of dietary fibre $(P=0 \cdot 001)$, riboflavin $(P=0.03)$ and iron $(P=0.04)$ were higher for children in the intervention school compared with the comparison school post-intervention. No significant differences were observed between schools for energy, thiamin, niacin and folate intake. The differences between schools for refined-grain intake, fibre, riboflavin and iron may be partly attributable to small decreases in intake by children in the comparison school. Modifying a variety of grain selections in the school cafeteria on a daily basis (i.e. whole-grain bread in place of white bread, whole-grain pasta in place of refined pasta, and utilising whole wheat flour in mixes instead of enriched white flour) accounted for the observed differences in availability and intake of whole-grain foods by children.

\section{Measurement variables for children}

Changes in psychosocial variables for children are presented in Table 5. Children in both the intervention and comparison schools demonstrated an increased ability to identify a whole-grain food, which reflected knowledge; however, a greater upward trend was noted for children in the intervention school $(P=0 \cdot 06)$. No significant differences were observed for usual food choice, availability of whole-grain foods in the home or self-efficacy for children.

\section{Intervention effects for parents}

Measurement variables for parents

Changes in psychosocial variables for parents are presented in Table 5. Self-reported intake of refinedgrain foods decreased significantly for parents in the intervention school compared with the comparison school post-intervention $(P<0 \cdot 01)$. Pre/post changes in role modelling $(P<0.001)$ and enabling behaviours $(P<0.05)$ were significantly greater for the intervention school than for the comparison school. No differences in perceptions of whole-grain health benefits or reported availability of whole-grain foods in the home were noted for parents.

\section{Programme implementation}

Feedback from parents regarding the newsletters and overall satisfaction with the programme was positive. The majority of parents $(78 \%)$ reported receiving most/all of the newsletters and greater than half (69\%) read most/all of them. Less than half ( $40 \%$ ) completed most/all of the 
Table 4 Changes in grain, energy and nutrient intakes by category for children

\begin{tabular}{|c|c|c|c|c|c|c|c|c|c|c|c|c|c|c|c|}
\hline \multirow[b]{3}{*}{ Grain category/nutrient } & \multicolumn{7}{|c|}{ Intervention school } & \multicolumn{7}{|c|}{ Comparison school } & \multirow{3}{*}{$\begin{array}{c}P \text { value for differences } \\
\text { between schools }\end{array}$} \\
\hline & \multirow[b]{2}{*}{$n$} & \multicolumn{2}{|c|}{ Pre } & \multicolumn{2}{|c|}{ Post } & \multicolumn{2}{|c|}{ Change from baselinet } & \multirow[b]{2}{*}{$n$} & \multicolumn{2}{|c|}{ Pre } & \multicolumn{2}{|c|}{ Post } & \multicolumn{2}{|c|}{ Change from baselinet } & \\
\hline & & Mean & SD & Mean & SD & Mean & SD & & Mean & SD & Mean & SD & Mean & SD & \\
\hline Whole grains (WG servings) & 56 & $0 \cdot 11$ & $0 \cdot 4$ & $1 \cdot 11$ & $1 \cdot 1$ & $1 \cdot 05^{\star}$ & $0 \cdot 2$ & 80 & 0.07 & $0 \cdot 2$ & $0 \cdot 16$ & 0.5 & 0.09 & $0 \cdot 1$ & 0.0001 \\
\hline Refined grains (RG servings) & 56 & 1.52 & $1 \cdot 4$ & 0.44 & $0 \cdot 6$ & $-1 \cdot 11^{*}$ & $0 \cdot 2$ & 80 & 1.52 & $1 \cdot 0$ & $1 \cdot 08$ & $1 \cdot 0$ & $-0 \cdot 46^{*}$ & $0 \cdot 2$ & 0.001 \\
\hline Some whole grain (SWG servings) & 56 & 0.24 & $0 \cdot 8$ & 0.04 & $0 \cdot 2$ & -0.20 & $0 \cdot 1$ & 80 & $0 \cdot 16$ & 0.5 & $0 \cdot 11$ & 0.4 & -0.05 & $0 \cdot 1$ & $0 \cdot 20$ \\
\hline Energy (kcal) & 56 & 495 & 237 & 516 & 200 & 7 & 259 & 80 & 439 & 180 & 404 & 221 & $-44^{\star}$ & 190 & $0 \cdot 19$ \\
\hline (MJ) & & $2 \cdot 07$ & 0.99 & $2 \cdot 16$ & 0.84 & 0.02 & 1.08 & & $1 \cdot 84$ & $0 \cdot 75$ & $1 \cdot 69$ & $0 \cdot 92$ & $-0 \cdot 18$ & $0 \cdot 79$ & \\
\hline Fibre (g) & 56 & $4 \cdot 1$ & $2 \cdot 4$ & $5 \cdot 3$ & $3 \cdot 1$ & $1 \cdot 3^{*}$ & $3 \cdot 7$ & 80 & $3 \cdot 8$ & $1 \cdot 9$ & $3 \cdot 5$ & $2 \cdot 0$ & -0.4 & $2 \cdot 4$ & 0.001 \\
\hline Thiamin (mg) & 56 & 0.41 & $0 \cdot 22$ & $0 \cdot 36$ & $0 \cdot 14$ & -0.04 & $0 \cdot 24$ & 80 & $0 \cdot 35$ & $0 \cdot 16$ & $0 \cdot 32$ & $0 \cdot 19$ & $-0.04^{*}$ & $0 \cdot 17$ & 0.90 \\
\hline Niacin (mg) & 56 & $5 \cdot 3$ & $4 \cdot 1$ & $5 \cdot 1$ & $3 \cdot 4$ & $-0 \cdot 1$ & $3 \cdot 9$ & 80 & $4 \cdot 6$ & $2 \cdot 8$ & $4 \cdot 0$ & $2 \cdot 5$ & $-0 \cdot 7$ & $3 \cdot 3$ & 0.34 \\
\hline Riboflavin (mg) & 56 & 0.48 & $0 \cdot 28$ & 0.52 & 0.27 & 0.03 & 0.24 & 80 & 0.50 & $0 \cdot 26$ & 0.45 & 0.29 & $-0.06^{*}$ & $0 \cdot 24$ & 0.03 \\
\hline Folate $(\mu \mathrm{g})$ & 56 & 100 & 92 & 92 & 80 & $-2 \cdot 6$ & 114 & 80 & 86 & 51 & 81 & 59 & -8 & 61 & 0.73 \\
\hline Iron (mg) & 56 & $3 \cdot 3$ & $1 \cdot 9$ & $3 \cdot 6$ & $2 \cdot 0$ & $0 \cdot 4$ & $2 \cdot 4$ & 80 & $3 \cdot 0$ & $1 \cdot 8$ & $2 \cdot 7$ & $1 \cdot 6$ & $-0 \cdot 4$ & $1 \cdot 7$ & 0.04 \\
\hline
\end{tabular}

SD, standard deviation.

'Significant pre/post difference within schools: $P<0.05$

+Difference $=$ Post - Pre.

Table 5 Changes in psychosocial variables related to Social Cognitive Theory (SCT) for children and parents

\begin{tabular}{|c|c|c|c|c|c|c|c|c|c|c|c|c|c|c|c|c|}
\hline \multirow[b]{3}{*}{ SCT construct (number of Items) } & \multirow[b]{3}{*}{ Range } & \multicolumn{7}{|c|}{ Intervention school } & \multicolumn{7}{|c|}{ Comparison school } & \multirow{3}{*}{$\begin{array}{l}P \text { value for differences } \\
\text { between schools }\end{array}$} \\
\hline & & \multirow[b]{2}{*}{$n$} & \multicolumn{2}{|c|}{ Pre } & \multicolumn{2}{|c|}{ Post } & \multicolumn{2}{|c|}{ Change from baselinet } & \multirow[b]{2}{*}{$n$} & \multicolumn{2}{|c|}{ Pre } & \multicolumn{2}{|c|}{ Post } & \multicolumn{2}{|c|}{ Change from baselinet } & \\
\hline & & & Mean & SD & Mean & SD & Mean & SD & & Mean & SD & Mean & SD & Mean & SD & \\
\hline \multicolumn{17}{|l|}{ Children } \\
\hline Whole-grain knowledge (6); $\alpha=0.49$ & $0-6$ & 59 & 3.9 & 1.5 & $5 \cdot 1$ & $1 \cdot 4$ & $1 \cdot 2^{*}$ & $1 \cdot 7$ & 80 & $3 \cdot 9$ & $1 \cdot 4$ & $4 \cdot 6$ & $1 \cdot 2$ & $0 \cdot 7^{\star}$ & 1.5 & 0.06 \\
\hline Usual food choice (7); $\alpha=0.62$ & $-7,+7$ & 58 & $2 \cdot 8$ & 1.9 & $2 \cdot 9$ & $2 \cdot 0$ & $0 \cdot 1$ & $1 \cdot 7$ & 78 & $2 \cdot 8$ & $1 \cdot 8$ & $2 \cdot 8$ & 1.9 & $0 \cdot 1$ & $1 \cdot 4$ & 0.96 \\
\hline $\begin{array}{l}\text { Availability of whole-grain foods in } \\
\text { the home (9); } \alpha=0.48\end{array}$ & $9-27$ & 56 & $19 \cdot 4$ & $3 \cdot 2$ & $19 \cdot 1$ & $3 \cdot 4$ & $-0 \cdot 3$ & $2 \cdot 5$ & 81 & $19 \cdot 4$ & $2 \cdot 3$ & $19 \cdot 7$ & $2 \cdot 4$ & $0 \cdot 2$ & $2 \cdot 1$ & $0 \cdot 22$ \\
\hline $\begin{array}{l}\text { Self-efficacy to choose whole-grain } \\
\text { foods (7); } \alpha=0.74\end{array}$ & $7-21$ & 54 & $18 \cdot 0$ & $3 \cdot 2$ & $18 \cdot 2$ & $3 \cdot 9$ & $0 \cdot 2$ & $3 \cdot 2$ & 81 & $19 \cdot 0$ & $2 \cdot 0$ & $19 \cdot 2$ & $2 \cdot 0$ & $0 \cdot 4$ & $2 \cdot 0$ & $0 \cdot 82$ \\
\hline \multicolumn{17}{|l|}{ Parents } \\
\hline Whole-grain food frequency scale (9); $\alpha=0.72$ & $0-18$ & 36 & $2 \cdot 1$ & $2 \cdot 0$ & $2 \cdot 0$ & 0.9 & $0 \cdot 2$ & $1 \cdot 7$ & 54 & $1 \cdot 9$ & $1 \cdot 2$ & $1 \cdot 9$ & $1 \cdot 0$ & $0 \cdot 1$ & $1 \cdot 1$ & 0.82 \\
\hline Refined-grain food frequency scale (3); $\alpha=0.71$ & $0-6$ & 40 & $1 \cdot 0$ & $1 \cdot 3$ & $0 \cdot 6$ & $0 \cdot 7$ & $-0 \cdot 3^{\star}$ & $0 \cdot 7$ & 63 & 0.6 & 0.5 & $0 \cdot 7$ & $0 \cdot 7$ & $0 \cdot 1$ & $0 \cdot 6$ & 0.01 \\
\hline Role modelling (5); $\alpha=0.63$ & $5-25$ & 40 & $13 \cdot 7$ & $3 \cdot 8$ & $15 \cdot 2$ & $3 \cdot 3$ & $2 \cdot 2^{*}$ & $2 \cdot 4$ & 65 & $13 \cdot 9$ & $3 \cdot 5$ & $14 \cdot 3$ & $3 \cdot 3$ & $0 \cdot 6$ & $2 \cdot 4$ & 0.001 \\
\hline Enabling behaviours (4); $\alpha=0.82$ & $4-20$ & 40 & $11 \cdot 2$ & $3 \cdot 4$ & $12 \cdot 9$ & $2 \cdot 8$ & $2 \cdot 3^{*}$ & $2 \cdot 9$ & 66 & $11 \cdot 0$ & $2 \cdot 9$ & $12 \cdot 2^{*}$ & $2 \cdot 9$ & $1 \cdot 3$ & $2 \cdot 1$ & 0.05 \\
\hline Whole-grain health benefits (3); $\alpha=0.81$ & $3-15$ & 39 & 12.9 & $2 \cdot 2$ & $12 \cdot 9$ & $2 \cdot 2$ & 0.4 & $2 \cdot 6$ & 63 & $12 \cdot 6$ & $1 \cdot 7$ & 12.9 & $2 \cdot 0$ & 0.3 & $1 \cdot 8$ & 0.84 \\
\hline $\begin{array}{l}\text { Availability of whole-grain foods } \\
\text { in the home }(9) ; \alpha=0.52\end{array}$ & $0-9$ & 35 & $1 \cdot 5$ & $4 \cdot 2$ & $2 \cdot 3$ & $3 \cdot 4$ & $1 \cdot \cdot 5^{*}$ & $3 \cdot 8$ & 64 & 1.5 & $2 \cdot 8$ & $2 \cdot 2$ & $3 \cdot 0$ & $0 \cdot 7$ & $3 \cdot 0$ & 0.24 \\
\hline
\end{tabular}

schools: $P<0.05$ 
parent/child activities. Overall participation in family activities was as follows: Quiz Bowl event at museum, $25 \%$; bakery tour, 38\%; grocery store tour, $16 \%$. The cafeteria log indicated that throughout the intervention whole-grain foods were served in the school cafeteria as planned $92 \%$ of the time. Most children participated in four (19\%) or five (78\%) classroom lessons. Completion of the in-class curriculum workbook activities was achieved by nearly all of the children (94\%).

\section{Discussion}

Outcomes from this feasibility study involving a multicomponent school-based intervention are suggestive of positive changes in the availability of whole-grain foods in the school environment and the consumption of whole-grain foods by children. Given that the typical intake of whole-grain foods by children has been only $0 \cdot 8-1 \cdot 0$ mean servings per day ${ }^{(7)}$, these positive findings have the potential to impact the long-term dietary habits of children. To our knowledge, this is the first reported multi-component school-based intervention designed to test the feasibility of increasing the intake of whole-grain foods by children. At the time the pilot study was conducted, the availability of whole-grain foods for school food service settings and awareness of these foods by food service staff were limited. Therefore this study represents important initial work in this setting to improve access to whole-grain foods by children.

Knowledge of whole-grain foods increased by children in both the intervention and comparison schools, although the intervention failed to produce significant changes in usual food choice, availability and self-efficacy related to children. Knowledge gains were reported in $71 \%$ of nutrition education studies reviewed by Lytle ${ }^{(27)}$. Results from the present study with regard to knowledge were consistent with these previous findings. Appropriate assessment items are needed that effectively measure the self-efficacy of children to select whole-grain foods in challenging situations both within and outside the home environment. However, establishing a firm knowledge base regarding whole-grain foods (i.e. identification and health benefits) is an essential first step before selfefficacy to select whole-grain foods in a variety of situations can be conceptualised. Furthermore, recent findings by Zabinski et al. ${ }^{(28)}$ suggested that the concept of selfefficacy may be closely associated with developmental stage. Self-efficacy was a significant predictor of fruit and vegetable intake for older adolescents (13-15-year-olds) but not for younger adolescents (11-12-year-olds). Our observed lack of change in the self-efficacy of 4th and 5th grade children may be attributed to this assumption.

Food preference development in children occurs through repeated tasting experiences with foods. Preference has been shown to be a major predictor of fruit and vegetable intake in previous studies with school-aged children ${ }^{(29-31)}$. Our pilot study supports the concept that whole-grain foods need to be available in schools to allow for frequent taste exposures for children. A potential barrier to enhanced preference of whole-grain foods by children may lie in the texture and appearance of whole-grain products as children tend to prefer foods with simple, smooth textures ${ }^{(32)}$. Utilising white whole wheat as an alternative to red wheat and changes in the milling and processing of whole grains may result in the development of new products that children find acceptable ${ }^{(33)}$.

This pilot study also suggested that parents in the intervention school had significantly higher role modelling and enabling behaviour scores post-intervention compared with parents in the comparison school. However, the intervention failed to produce significant changes related to the frequency of whole-grain intake, availability of wholegrain foods in the home and perceptions of health benefits for parents. This finding is not surprising given that the mean scores for the whole-grain health benefits and home availability scales were quite high at baseline, leaving limited room for improvement. A possible explanation for the minimal change in home availability of whole-grain foods could be the confusion and difficulties associated with identifying whole-grain foods at the point of purchase for consumers. Barriers related to identification lead to decreased selection and subsequently limited availability of whole-grain foods in the home. An important prerequisite is educating parents about the importance of repeated taste experiences with new whole-grain foods for their children combined with creative ways to incorporate these foods into family meals.

Despite offering creative family-oriented activities, overall parent involvement with the programme was low; a finding that is consistent with previous nutrition interventions $^{(34,35)}$. In contrast to these findings, Perry et al. ${ }^{(36)}$ reported that parental involvement in an intervention programme is feasible and a critical component that enhances positive behavioural changes for school-aged children. The Hearty Heart and Friends Program utilised an approach that was 'do-at-home, game-oriented, and easy'. Identification of parent-friendly strategies that promote active sustained participation is critical to the overall effectiveness and sustainability of an intervention programme. In terms of our findings, extending the length of our intervention programme (i.e. providing an increased dose) may have increased the availability of whole-grain foods in the home environment and intake by parents.

This pilot project had several strengths and limitations that need to be addressed when interpreting the findings. Strengths of this project included development of a multicomponent, school-based intervention based on the model of previously successful interventions to increase fruit and vegetable intake of children. Second, mediating variables were included within the intervention model which previously had been shown to be amenable to 
behavioural change in children based on a review of the literature. Finally, a comprehensive nutrient software program with whole-grain food grouping capabilities was used to estimate whole-grain intake of children using data obtained from meal observations.

This pilot study was designed to provide limited information from two schools about the feasibility of an intervention in preparation for a larger controlled, randomised school-based study. A major limitation is that the data are insufficient to deconfound the experimental effect from any school-by-time component of variance. Preliminary external data of whole-grain intake in children in grades 4-6 in four schools yielded an estimate of the $\mathrm{ICC}_{\mathrm{schoo} \times \text { time }}\left(\mathrm{ICC}_{\mathrm{s} \times \mathrm{t}}\right)$ for change as 0 ( $\mathrm{PJ}$ Hannan, personal communication). If we use this external estimate of ICC $_{\mathrm{s} \times \mathrm{t}}$ the standard errors and $P$ values would be as shown. However this estimate is itself imprecise; the ICC $_{s \times t}$ is less than 0.02 with about $50 \%$ probability. If $\mathrm{ICC}_{\mathrm{s} \times \mathrm{t}}=0.02$ the standard errors should be inflated by $\mathrm{DEFt}=\sqrt{ }(1+64 \times 0 \cdot 02)=1 \cdot 5^{(37)}$. The conclusions regarding the two major outcomes related to whole- and refined-grain intake (Table 4) would remain. Use of a convenience sample limited the generalisability to other population groups. Other potential limitations included race/ethnicity differences between schools and the short duration of the intervention programme. Although racial/ ethnic differences were observed between participants in the two schools due to challenges in recruitment for the intervention school, this finding did not appear to adversely affect the observed outcomes. Overall, positive behavioural changes (i.e. increased intakes of whole grains, increased knowledge of whole-grain foods) were observed for children in the more ethnically diverse school. Selection bias in this pilot study is a concern due to the constraints associated with recruitment of 5 th grade students in the intervention school and the large respondent burden for parents and children. Interventionists may encounter barriers unique to the school environment that may affect recruitment and selection of participants. This study was conducted with external personnel teaching the lessons, working with food service professionals to modify menus, and conducting the family events. Therefore a limitation of the study is the lack of information on the feasibility of classroom teachers implementing the programme. External support may be needed for future implementation which includes activities conducted outside the classroom. Furthermore, the low alpha coefficients for whole-grain knowledge and availability measures are a limitation and indicate that further psychometric development of these measures is required. In addition, although meal observations are a reliable method for collecting dietary intake data of children, potential observer errors including the fact that the observers were unblinded to the intervention group could have resulted in under- or over-reporting of whole-grain intake of children.

\section{Application}

Findings from this pilot study demonstrated that wholegrain foods can be successfully incorporated into the school environment and that greater availability can result in increased whole-grain consumption by children to levels closer to current recommendations. Changes brought about by this intervention programme are expected to contribute to overall improvement in eating habits and long-term health of children. The successful outcome of this research has direct relevance to the National School Lunch Program and policies regarding the inclusion of additional whole-grain foods served in school meals. Collaborative research endeavours between academia and industry in the future could result in the development of consumer-friendly whole-grain products.

Future research aimed at the implementation of a randomised, multi-component school-based intervention on a broader scale is recommended with a study design that would allow for independent measurements of the effect size of the three experimental components on whole-grain consumption (cafeteria menu modification, classroom curriculum and family involvement component). Many previous interventions to change the dietary intake of children have been multi-component based on behaviour change theories and have not measured the separate effects of the individual components. Given that parental involvement in the current pilot study was low $(25 \%)$ and costly in terms of implementation, having measures of the separate effects of the individual components would allow interventionists to select the most effective components that produce increased intake. Furthermore, additional research that addresses the availability of whole-grain foods in the marketplace and the effectiveness of messages on product labels directed to consumers is needed.

\section{Acknowledgements}

This pilot study was supported by a grant from the Allen Foundation Michigan. The authors wish to thank the children and parents who participated in this study. We also recognise the invaluable contributions of the following: teachers, principals and food service staff of the Hopkins School District, Great Harvest Bread Company, Con Agra Foods, Inc., Cub Foods, Supervalu Eden Praire, $\mathrm{MN}$ and Mill City Museum Minneapolis, MN.

\section{References}

1. Slavin J (2004) Whole grains and human health. Nutr Res Rev 17, 1-12.

2. Slavin JL, Jacobs D, Marquart L \& Wiemer K (2001) The role of whole grains in disease prevention. J Am Diet Assoc 101, 780-785.

3. US Department of Agriculture, Center for Nutrition Policy and Promotion (2005) The Food Guide Pyramid. Washington, DC: US Government Printing Office. 
4. US Department of Health and Human Services, Office of Disease Prevention and Health Promotion (2000) Healthy People 2010, vols. I and II. Washington, DC: US Government Printing Office.

5. Krauss R, Eckel R, Howard B, Daniels S, Kris-Etherton P, Lichtenstein A, Wylie-Rosett J \& Bazzarre T (2001) American Heart Association Dietary Guidelines. Revision 2000: A statement for healthcare professionals from the Nutrition Committee of the American Heart Association. Circulation 102, 2284.

6. Kushi LH, Byers T, Doyle C, Bandera EV, McCullough M, McTiernan A, Gansler T, Andrews KS \& Thun MJ; American Cancer Society (2006) Nutrition and Physical Activity Guidelines Advisory Committee. American Cancer Society Guidelines on Nutrition and Physical Activity for cancer prevention: reducing the risk of cancer with healthy food choices and physical activity. CA Cancer J Clin 56, 254-281.

7. Cook AJ \& Friday JE (2005) CNRG Table Set 3.0: Pyramid Servings Intakes in the United States, 1999-2002, 1 Day. Beltsville, MD: US Department of Agriculture, Agricultural Research Service; available at http://www.ars.usda.gov/ Services $/$ docs.htm?docid $=8503$

8. United States Department of Agriculture, Food and Nutrition Service (2007) National School Lunch Program. http:// www.fns.usda.gov/cnd/Lunch/AboutLunch/NSLPFactSheet. pdf (accessed November 2007).

9. Baranowski T, Perry CL \& Parcel GS (2002) How individuals, environments, and health behavior interact: social cognitive theory. In Health Behavior and Health Education: Theory, Research, and Practice, 3rd ed., pp. 165-184 [K Glanz, FM Lewis and BK Rimer, editors]. San Francisco, CA: Jossey-Bass.

10. French SA \& Stables G (2003) Environmental interventions to promote vegetable and fruit consumption among youth in school settings. Prev Med 37, 593-610.

11. Burgess-Champoux T, Marquart L, Vickers Z \& Reicks M (2006) Perceptions of children, parents and teachers regarding whole grain foods and implications for a school-based intervention. J Nutr Educ Behav 38, 230-237.

12. Anon (2006) Program schools children in whole grain nutrition. Today's Dietitian 8, 66

13. Lafferty A, Marquart L \& Reicks M (2006) Hunt for whole grains in the grocery store. J Nutr Educ Behav 38, 197-198.

14. Baglio ML, Domel Baxter S, Gunn CH, Thompson WO, Schaffer NM \& Frye FHA (2004) Assessment of interobserver reliability in nutrition studies that use direct observation of school meals. J Am Diet Assoc 104, 1385-1392.

15. Simons-Morton BG, Forthofer R, Wei Huang I, Baranowski T, Reed DB \& Fleishman R (1992) Reliability of direct observation of schoolchildren's consumption of bag lunches. J Am Diet Assoc 92, 219-221.

16. Gray C, Lytle LA, Mays R, Taylor G, Perry C \& Story M (2002) Foods on student's trays when they leave the cafeteria line as a proxy for foods eaten at lunch in a school-based study. J Am Diet Assoc 102, 407-409.

17. Baranowski T, Dworkin R, Henske JC, Clearman DR, Dunn JK, Nader PR \& Hooks PC (1986) The accuracy of children's self-reports of diet: Family Health Project. J Am Diet Assoc 86, 1381-1385.

18. US Department of Health and Human Services and US Department of Agriculture (2005) Dietary Guidelines for Americans, 2005, 6th ed. Washington, DC: US Government Printing Office.

19. Bere E \& Klepp KI (2003) Reliability of parental and selfreported determinants of fruit and vegetable intake among 6th graders. Public Health Nutr 7, 353-356.
20. Stevens J, Cornell CE, Story M, French SA, Levin S, Becenti A, Gittelsohn J, Going SB \& Reid R (1999) Development of a questionnaire to assess knowledge, attitudes, and behaviors in American Indian children. Am J Clin Nutr 69, $773 \mathrm{~S}-781 \mathrm{~S}$.

21. Birnbaum AS, Lytle LA, Murray DM, Story M, Perry CL \& Boutelle KN (2002) Survey development for assessing correlates of young adolescent's eating. Am J Health Behav 26, 284-295.

22. Parcel GS, Edmundson E, Perry CL, Feldman HA, O'HaraTompkins N, Nader PR, Johnson CC \& Stone EJ (1995) Measurement of self-efficacy for diet-related behaviors among elementary school children. J Sch Health 65, 23-27.

23. Marsh T, Cullen KW \& Baranowski T (2003) Validation of a fruit, juice, and vegetable availability questionnaire. $J$ Nutr Educ Behav 35, 93-97.

24. Block G, Hartman AM, Dresser CM, Carroll MD, Gannon J \& Gardner L (1986) A data-based approach to diet questionnaire design and testing. Am J Epidemiol 124, 453-469.

25. Cody RP \& Smith JK (2006) Applied Statistics and the SAS Programming Language, 5th ed. Upper Saddle River, NJ: Pearson Prentice Hall.

26. Murray DM (1998) The Design and Analysis of Group Randomized Trials. New York: Oxford University Press.

27. Lytle L (1994) Nutrition Education for School-aged Children: A Review of Research, pp. 1-63. Washington, DC: Office of Analysis and Evaluation.

28. Zabinski MF, Daly T, Norman GJ, Rupp JW, Calfas KJ, Sallis JF \& Patrick K (2006) Psychosocial correlates of fruit, vegetable, and dietary fat among adolescent boys and girls. J Am Diet Assoc 106, 814-821.

29. Vereecken CA, Van Damme W \& Maes L (2005) Measuring attitudes, self-efficacy, and social environmental influences on fruit and vegetable consumption of 11- and 12-year old children: reliability and validity. J Am Diet Assoc 105, 257-261.

30. De Bourdeaudhuij I, Klepp KI, Due P, Perez Rodrigo C, de Almeida MDV, Wind M, Krolner R, Sandvik C \& Brug J (2004) Reliability and validity of a questionnaire to measure personal, social and environmental correlates of fruit and vegetable intake in 10-11-year old children in five European countries. Public Health Nutr 8, 189-200.

31. Domel SB, Thompson WO, Davis HC, Baranowski T, Leonard SB \& Baranowski J (1996) Psychosocial predictors of fruit and vegetable consumption among elementary school children. Health Educ Res 11, 299-308.

32. Urbick B (2002) Kids have great taste: an update to sensory work with children. Presented at Annual Meeting Institute of Food Technologists, Anaheim, CA, 15-19 June.

33. Smith Edge M, Miller Jones J \& Marquart L (2005) A new life for whole grains. J Am Diet Assoc 105, 1856-1860.

34. Harrington KF, Franklin FA, Davies SL, Shewchuk RM \& Brown Binns M (2005) Implementation of a family intervention to increase fruit and vegetable intake: The Hi5+ experience. Health Promot Pract 6, 180-189.

35. Nader PR, Sellers DE, Johnson CC, Perry CL, Stone EJ, Cook KC, Bebchuk J \& Luepker RV (1996) The effect of adult participation in a school-based family intervention to improve children's diet and physical activity: The Child and Adolescent Trial for Cardiovascular Health. Prev Med 25, 455-464.

36. Perry CL, Luepker RV, Murray DM, Kurth C, Mullis R, Crockett S \& Jacobs DR (1998) Parent involvement with children's health promotion: The Minnesota home team. Am J Public Health 78, 1156-1160.

37. Kish L (1965) Survey Sampling. New York: John Wiley and Sons. 